\title{
Risso's and Pacific white-sided dolphin habitat modeling from passive acoustic monitoring
}

\author{
Melissa S. Soldevilla ${ }^{1,4, *}$, Sean M. Wiggins ${ }^{1}$, John A. Hildebrand ${ }^{1}$, Erin M. Oleson ${ }^{1,2}$, \\ Megan C. Ferguson ${ }^{3}$ \\ ${ }^{1}$ Scripps Institution of Oceanography, University of California, San Diego, 9500 Gilman Dr. \#0205, La Jolla, \\ California 92093-0205, USA \\ ${ }^{2}$ NOAA-NMFS-Pacific Islands Fisheries Science Center, 1601 Kapiolani Blvd. Ste. 1110, Honolulu, Hawaii 96814, USA \\ ${ }^{3}$ National Marine Mammal Laboratory, Alaska Fisheries Science Center, NOAA Fisheries, 7600 Sand Point Way NE F/AKC3, \\ Seattle, Washington 98115-6349, USA \\ ${ }^{4}$ Present address: Duke University Marine Laboratory, 135 Duke Marine Lab Road, Beaufort, North Carolina 28516, USA
}

\begin{abstract}
Habitat characterization allows prediction of dolphin distributions in response to oceanographic processes and can be used to understand and predict effects of anthropogenic disturbances. Many habitat models focus on contemporary dolphin occurrence and environmental predictor data, but time-lagged oceanographic data may increase a model's predictive power due to ecological successional processes. Using hourly occurrence of Risso's dolphin Grampus griseus clicks and 2 types of Pacific white-sided dolphin Lagenorhynchus obliquidens clicks in autonomous passive acoustic recordings, we investigate the importance of time-lagged predictor variables with generalized additive models. These models relate dolphin acoustic activity from recordings at 6 sites in the Southern California Bight between August 2005 and December 2007 to oceanographic variables including sea surface temperature (SST), SST coefficient of variation (CV), sea surface chlorophyll concentration (chl), chl CV, upwelling indices, and solar and lunar temporal indices. The most consistently selected variables among the trial models evaluated during cross-validation were SST (100\% of models) and SST CV (80\%) for Risso's dolphin clicks; solar indices (100\%) and SST and SST CV (60\% each) for Pacific white-sided type A (PWS A) clicks; and SST CV (100\%), solar indices $(100 \%)$ and SST $(80 \%)$ for Pacific white-sided type B (PWS B) clicks. Best predictive models for Risso's dolphins and PWS A clicks included time-lagged variables, suggesting the importance of ecological succession between abiotic variables and dolphin occurrence, while best models of PWS B clicks were for current conditions, suggesting association with prey-aggregating features such as fronts and eddies.
\end{abstract}

KEY WORDS: Risso's dolphin - Grampus griseus · Pacific white-sided dolphin · Lagenorhynchus obliquidens $\cdot$ Habitat model $\cdot$ Generalized additive model $\cdot$ Passive acoustic monitoring $\cdot$ Southern California Bight

\section{INTRODUCTION}

Conservation scientists and resource managers may be able to improve delphinid distribution and abundance estimates by developing quantitative predictive habitat models that relate the abundance or distribution of these marine predators to the distribution of their prey and the underlying physical oceanography (Redfern et al. 2006). Most quantitative cetacean habitat models have been built from ship-based and aerialbased visual survey data (Forney 2000, Ferguson et al. 2006, Becker 2007). These visual surveys are capable of covering large spatial areas, but are limited in their temporal coverage due to survey platform, personnel 
and cost constraints. The inability to sample during night and rough weather conditions may affect the accuracy or precision of resulting models. Additionally, visual survey data are limited to times when cetaceans are conspicuous at the surface. Models based on these data may not represent 'prime' habitat (i.e. habitat that is important to feeding or breeding, and hence the animals' overall fitness) if the animals are more easily observed when resting or transiting to such key areas (Hamazaki 2002). Alternate sampling methods, such as passive acoustic monitoring, may provide a better representation of cetacean presence and activity in prime habitats and thereby improve model accuracy and precision.

The accuracy and precision of habitat models is also dependent on the environmental data upon which they are built. Habitat models developed for predictive purposes should include environmental variables that are easily accessible and available across regions and times of interest (Hamazaki 2002, Becker 2007), such as remotely sensed sea surface temperature, chlorophyll, and altimetry data, upwelling indices, and bathymetric descriptors. While increased delphinid occurrence may result from increased prey abundance related to biological and physical oceanographic conditions (Jaquet \& Whitehead 1996, Fiedler et al. 1998), measures of prey abundance are not readily attainable and oceanographic conditions are often used as proxies. The relationship between delphinid occurrence and oceanographic variables, such as sea surface temperature, upwelling and phytoplankton abundance, may include a time lag depending on whether zooplankton blooms are created by successional or aggregational mechanisms (Jaquet 1996, Gregr \& Trites 2001, Croll et al. 2005). For successional zooplankton blooms, a lag time may be as great as 4 mo between initial physical oceanographic conditions, phytoplankton bloom development, zooplankton bloom development and the aggregation of fish, squid and dolphins (Vinogradov 1981). Conversely, aggregational zooplankton blooms, such as those found at convergence zones where downwelling aggregates buoyant organisms, are related to current oceanographic conditions (Gregr \& Trites 2001). This mechanistic difference in zooplankton bloom development may bias the successful dolphin habitat models based on contemporaneous (zero-lagged) remotely sensed data toward those that describe or quantify aggregational systems.

The development of habitat models that include acoustic delphinid survey data and time-lagged environmental variables may improve their predictive power. Autonomous, fixed-sensor, passive acousticbased surveys offer a technique to assess dolphin occurrence over long periods, in remote locations, dur- ing adverse weather conditions and during nighttime periods. Recent spectral analysis of Risso's dolphin (Grampus griseus) and Pacific white-sided dolphin (Lagenorhynchus obliquidens) echolocation clicks off southern California revealed the existence of species and possibly sub-species click types (Soldevilla et al. 2008) that can be used to examine their occurrence in autonomous acoustic data. Sampling delphinid echolocation clicks, which are produced most frequently during foraging activities (Norris et al. 1994, BarrettLennard et al. 1996, Van Parijs \& Corkeron 2001, Nowacek 2005), also increases the likelihood that models represent prime foraging habitat. While these methods excel at temporal coverage, fixed-sensors placed at multiple sites can be sampled to increase spatial coverage. Finally, the inclusion of temporal lags to environmental data in habitat models may improve predictive power and lead to hypotheses about the mechanisms causing prey aggregation.

This study investigates the utility of incorporating time-lagged oceanographic data into predictive habitat models of dolphin acoustic occurrence. Habitat models are built within a generalized additive model (GAM) framework and incorporate autonomously recorded echolocation click occurrence with remotely sensed oceanographic variables, upwelling indices, and solar and lunar temporal indices. GAMs offer a flexible regression technique for modeling the importance of environmental correlates for habitat prediction (Hastie \& Tibshirani 1990) and are commonly utilized in studies of marine habitat. Forward-backward selection and cross-validation methods are employed to select models with the best predictive power. We investigate the hypotheses that (1) the inclusion of readily available oceanographic predictor variables results in models with better ability to predict dolphin occurrence than the null model in which predictor variables are absent and (2) the inclusion of timelagged predictor variables results in models with better predictive abilities than those built on zero-lagged data.

\section{MATERIALS AND METHODS}

Study area and animals. The Southern California Bight (SCB) (Fig. 1) is a highly productive upwelling region characterized by 3 environmental features: (1) the California Current, an equatorward flowing eastern boundary current (Reid et al. 1958, Wooster \& Jones 1970); (2) the Southern California Eddy, a large counterclockwise gyre within the bight (Reid et al. 1958, Hickey 1979); and (3) complex bathymetry including high islands and banks, and low troughs and basins (Shepard \& Emery 1941, Emery 1960) that lead 


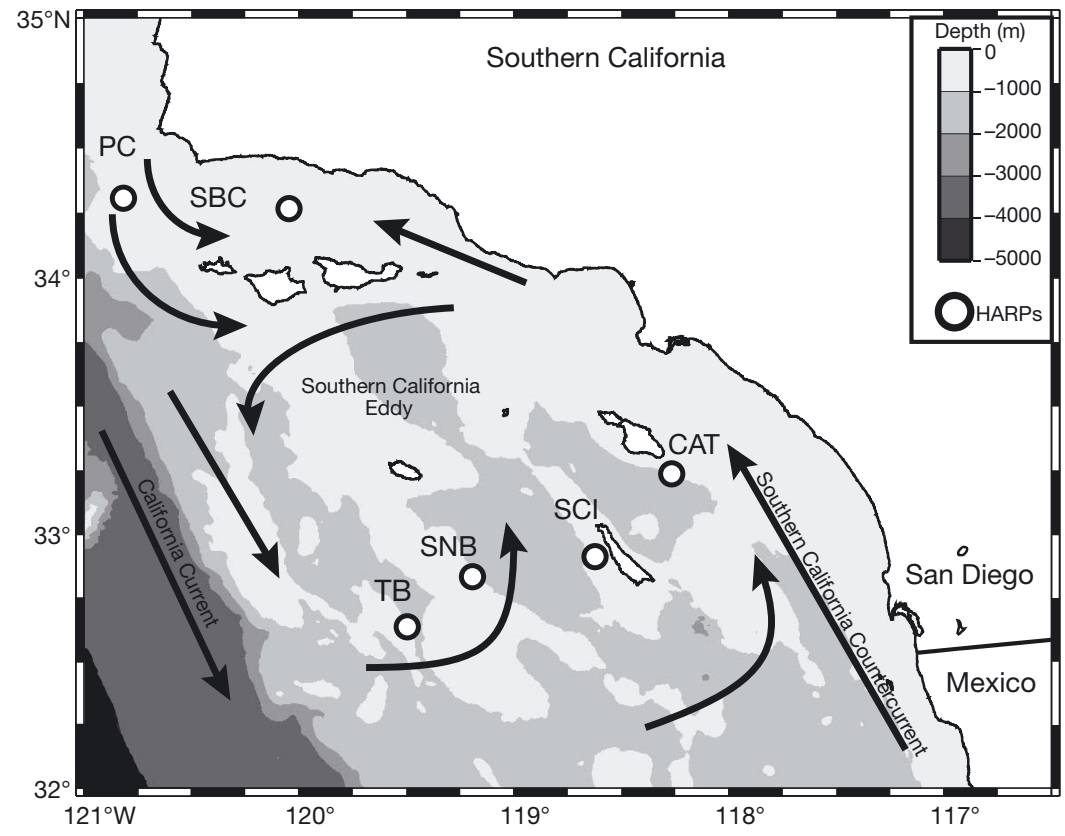

Fig. 1. Study area including the current circulation patterns and locations of High-frequency Acoustic Recording Package (HARP) deployment sites. Depths are indicated by grayscale bar. Sites: $\mathrm{PC}=$ Point Conception; $\mathrm{SBC}=$ Santa Barbara Channel; TB = Tanner Basin; SNB = San Nicholas Basin; SCI $=$ San Clemente Island $;$ CAT $=$ Santa Catalina Island. Current circulation map adapted from Hickey (1992)

to formation of mesoscale (50 to $200 \mathrm{~km}$ ) and submesoscale (1 to $50 \mathrm{~km}$ ) eddies throughout the bight (Kolpack 1971, Brink \& Muench 1986, DiGiacomo \& Holt 2001, Caldeira et al. 2005).

Risso's dolphins are relatively large, tropical to temperate odontocetes that feed nearly exclusively on cephalopods (Leatherwood et al. 1980, Clarke \& Pascoe 1985, Clarke 1996). Pacific white-sided dolphins, a cold-temperate pelagic species endemic to the North Pacific Ocean (Leatherwood et al. 1984, Barlow \& Forney 2007), forage opportunistically on epipelagic and mesopelagic schooling fishes and cephalopods (Brown \& Norris 1956, Fitch \& Brownell 1968, Stroud et al. 1981, Walker et al. 1986). Both Risso's and Pacific white-sided dolphins exhibit high seasonal and interannual variability in occurrence and distribution off southern California (Green et al. 1992, Shane 1994, Forney \& Barlow 1998, Kruse et al. 1999, Benson et al. 2002, Barlow \& Forney 2007). Risso's dolphin habitat around the world is characterized by steep bathymetry and warm waters (Dohl et al. 1983, Green et al. 1992, Baumgartner 1997, Baumgartner et al. 2001), whereas Pacific white-sided dolphin habitat is characterized by cool waters near the shelf-break (Benson et al. 2002, Yen et al. 2004, Becker 2007). Off southern California, Risso's dolphins produce one species-specific click type with distinct spectral patterns, while Pacific white-sided dolphins produce 2 spectrally distinct click types, denoted types PWS A and PWS B (Soldevilla et al. 2008, 2010a,b). Spatial and temporal trends in PWS A and PWS B click occurrence support the hypothesis that these click types respectively represent the morphologically and genetically distinct northern and southern populations that overlap in the SCB (Walker et al. 1986, Lux et al. 1997, Soldevilla et al. 2010b).

Acoustic data. Acoustic data collection and click detection methods have been described previously (Soldevilla et al. 2008, 2010a,b). Briefly, echolocation clicks of 3 types (Risso's, PWS A and PWS B) were detected in time series of 1 to 4 mo duration from 30 autonomous High-frequency Acoustic Recording Package (HARP) deployments at 6 SCB locations between August 2005 and December 2007 (Fig. 1). To quantify important dolphin habitat while reducing the autocorrelation inherent in time-series data, the duration that dolphins spend echolocating at each site per week is used as a dependant variable in habitat models. For each click type, hourly click bout occurrence was summed to obtain the total hours per week with acoustic detections. Echolocation clicks of medium-sized odontocetes may be detectable up to $9 \mathrm{~km}$ for on-axis orientations (Ward et al. 2009), though 4 to $5 \mathrm{~km}$ may be a more reasonable detection estimate given variability in animal orientations (Marques et al. 2009). Therefore, the temporal and spatial resolutions of the dependant variable are $1 \mathrm{wk}$ and approximately a $5 \mathrm{~km}$ radius, respectively.

Temporal coverage at the 6 sites is variable due to instrument servicing ship time constraints, occasional instrument failures, and recording sampling schedules (Fig. 2). Two-thirds of the available acoustic data were sampled continuously, while the remaining data were recorded on a sampling schedule of $5 \mathrm{~min}$ 'on' and either 5, 10, or $15 \mathrm{~min}$ 'off' for a given deployment. Scheduled recording may decrease the probability of detecting calling bouts. Therefore, the detection probabilities were estimated for the 3 sampling schedules by subsampling continuous data as follows. For each hour of $23609 \mathrm{~h}$ of continuous data, 60 permutations, starting at each minute of the hour, were conducted with 5 min sampled followed by $X$ min omitted (where $X=5,10$ or $15 \mathrm{~min}$ ). For each subsampled hour, click type presence or absence was determined for each of the 60 permutations and the hourly probability of detection was calculated as the mean of the 60 permu- 


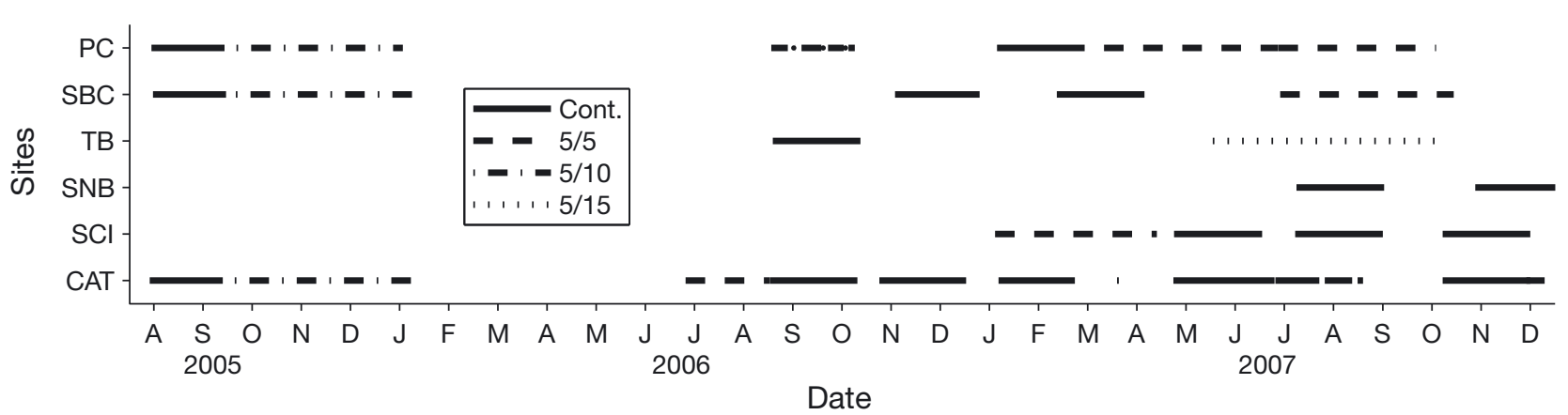

Fig. 2. High-frequency Acoustic Recording Package (HARP) data availability and sampling schedule at each of 6 sites in the Southern California Bight (SCB). Data availability is indicated by presence of a line at each site while sampling schedule (continuous, $5 \mathrm{~min}$ on/5 $\mathrm{min}$ off, $5 \mathrm{~min}$ on/10 $\mathrm{min}$ off, an $5 \mathrm{~min}$ on/15 min off) is indicated by line type. See Fig. 1 for abbreviations

tations. Hourly probabilities were averaged across all hours and sites to obtain a single detection probability for each click type at each sample level. Site-specific detection probabilities were not utilized due to low sample sizes at some sites; detection probabilities did not differ significantly between sites.

Environmental data. Lunar cycles (US Naval Observatory, http://aa.usno.navy.mil), upwelling indices (Pacific Fisheries Environmental Laboratory, www.pfeg. noaa.gov/products/PFEL/modeled/indices/upwelling/ upwelling.html), and remotely sensed satellite data (M. Kahru, Scripps Institution of Oceanography, http:// spg.ucsd.edu/Satellite_Data/California_Current/) were readily accessible from internet databases for use as predictor variables. A weekly solar index, included to account for seasonal effects, numbered weeks sequentially from 1 to 52 starting with the first day of the year. Nighttime lunar duration, a continuous proxy for lunar phase, was calculated as the duration that the moon was above the horizon while the sun was below the horizon each week. The daily coastal upwelling index, an index of the strength of the wind forcing on the ocean, was available as a single value for the entire $\mathrm{SCB}$, representing the average upwelling over a $3^{\circ} \times 3^{\circ}$ $(333 \times 333 \mathrm{~km})$ region centered at $33^{\circ} \mathrm{N}$ and $119^{\circ} \mathrm{W}$. Daily upwelling indices were averaged over $7 \mathrm{~d}$ periods. Seven day composites of sea surface temperature (SST) and chlorophyll concentration (chl) at $1 \mathrm{~km}^{2}$ resolution provide fine spatial and temporal resolution of oceanographic variation while minimizing missing data caused by cloud coverage (e.g. Becker 2007). Using WIM \& WAM software (www.wimsoft.com), spatially averaged mean SST and chl time series were obtained for an area defined by a $20 \mathrm{~km}$ radius centered around each of the 6 HARP sites. Output statistics from wam_statist for each area included total number of $1 \mathrm{~km}^{2}$ pixels, number of pixels with valid data, mean value of pixels, and standard deviation of pixel values. Weekly samples with less than $5 \%$ valid data due to cloud cover were omitted to prevent use of non-representative data. Coefficients of variation (CVs) in the spatial domain were calculated from the WAM output statistics for both SST and chl as proxies for temperature and productivity fronts (e.g. Becker 2007). Mean SST and chl are highly correlated as a result of increased productivity associated with cold, nutrient-rich upwelled waters. Predictor variables in a GAM model should be independent and orthogonal (Hastie \& Tibshirani 1990). To prevent the model from fitting correlated predictor variables, $\log _{10} \mathrm{chl}$ was regressed against SST and residual $\log _{10} \mathrm{chl}$ values were included in the model terms instead.

Habitat model analysis. The relationships between dolphin acoustic activity and environmental variables were investigated within a GAM framework (Hastie \& Tibshirani 1990). The GAM, a nonparametric extension of the generalized linear model, may be represented as

$$
g(\mu)=\alpha+\sum_{j=1}^{p} f_{j}\left(X_{j}\right)
$$

in which $g(\mu)$, the link function, relates functions of the additive predictor variables, $\alpha+\sum_{j=1}^{p} f_{j}\left(X_{j}\right)$, to the mean of the response variable, $\mu$. The link function allows specification of alternative distributions for nonnormally distributed response data. Errors of discrete count data are often well approximated with a Poisson error distribution, but the typical clumping of behavioral data leads to over-dispersion of errors (McCullagh \& Nelder 1999). In this study, the response variable, number of hours per week with click type present, was modeled as an over-dispersed Poisson distribution. The right side of the equation is the additive predictor, which can incorporate nonparametric forms $f_{j}\left(X_{j}\right)$ (such as smoothing splines) in GAMs, allowing greater flexibility in fitting relationships of the predictor variables. The predictor variables included in this model are: mean SST, residual chl, SST $\mathrm{CV}$, chl CV, upwelling index, lunar duration, and the 
interaction of week and region (week $\times$ region). This last term was included with a factorial interaction for region (i.e. north vs. south) due to known differences in seasonal occupation within the SCB (Soldevilla et al. 2010a,b). To account for decreased probability of detection due to incomplete weekly coverage and sampling schedule, an offset term $(\alpha)$ was included for each sample to account for (1) number of hours per week with recordings and (2) the appropriate reciprocal of detection probability.

S-Plus 6.0 (Insightful) was used to build and compare GAM models for each of the 3 click types. Multiple models were built to compare hypotheses of the effect of temporal lag in environmental data on the occurrence of dolphin clicks. Depending on the mechanisms of prey aggregation, lag times between environmental data and the occurrence of dolphins may range from 0 to 16 wk. While it is likely that lag times differ between environmental variables, inclusion of all possible lag times for each variable would make the model selection process unnecessarily complex. Therefore, we explored a wide breadth of individual models that were created from environmental data at only $0,1,2,4$, 8 , and 16 wk time lags. To approximate an over-dispersed Poisson distribution for the response variable, the S-Plus quasi-likelihood distribution was modeled with a logarithmic link function and variance proportional to the mean. Models were constructed with options for linear terms and smoothing splines with less than 3 degrees of freedom. This allowed the flexibility of incorporating non-linear effects while restricting unrealistic complexity that might be difficult to interpret ecologically (Forney 2000, Ferguson et al. 2006). S-Plus does not accommodate factorial spline interaction terms, therefore week was modeled as a polynomial fit.

To ensure the models contained only significant terms, model development incorporated the forward/ backward stepwise selection of variables using the SPlus function step.gam. Akaike's Information Criterion (AIC) was used to determine the best model at each step of the forward/backward selection process. To improve estimation of the dispersion parameter and allow selection of higher order spline fits when appropriate, stepwise selection of variables occurred twice for each model, following Ferguson et al. (2006). The first call to the stepwise selection process started with the null model and included only higher order terms, while the second call to the selection process began with the best model from the first call and included functions with 1 degree of freedom.

Use of AIC can over-fit a model to the data, leading to lower predictive ability. Therefore, a cross-validation approach was used to assess the predictive power of a number of models. Studies that incorporate spa- tially rich surveys over several years typically assess predictive power through a cross validation approach in which survey data from a single year is omitted and the model is tested on this novel dataset (e.g. Forney 2000, Hastie et al. 2005, Ferguson et al. 2006, Becker 2007). In contrast, this study is temporally rich at several sites, so a cross-validation approach was used in which contiguous blocks of time from individual sites comprised the out-set for model testing. Removal of a large block of related data (e.g. from 1 year or 1 site) would result in stronger tests than removal of randomly selected samples. However, Soldevilla et al. $(2010 \mathrm{a}, \mathrm{b})$ found site-specific and seasonal differences in dolphin occurrences. Given the uneven sampling effort across sites, exclusion of seasons or years of data at a single site from the model-building process may result in low predictive power of these tests. A compromise was developed in which $20 \%$ of the data were removed as a series of 4 randomly selected smaller blocks of time from individual sites, ensuring that no more than 13 consecutive wk at a single site were removed at a time. In this manner, a cross-validation approach that used $80 \%$ of the data to develop models and removed $20 \%$ of the data for use in evaluation was implemented. Therefore, for each click type, the stepwise building procedure was performed on 5 datasets, i.e. combinations of data with a different $20 \%$ of the data left out, which resulted in 5 best models. The best of these 5 models was selected by comparing crossvalidation performance using predict.gam and selecting the model with the lowest average squared prediction errors (ASPEs) on its novel evaluation data.

Time series of delphinid occurrence and environmental data included in the habitat models are available online; see supplement at www.int-res.com/ articles/suppl/m423p247_supp.pdf.

\section{RESULTS}

HARP recordings contained 251 week-long samples from deployments at 6 sites in the SCB. Of these 251 samples, Risso's dolphin, PWS A and PWS B clicks were detected in 101, 71, and $30 \mathrm{wk}$, respectively. Over $80 \%$ of the weeks contained complete recordings with $168 \mathrm{~h}$, and all weeks contained at least 6 full days $(144 \mathrm{~h})$ of recorded time. The maximum hours per week containing Risso's dolphin and PWS A and PWS B clicks were 84, 54, and $98 \mathrm{~h}$, respectively, while mean hours per week with click detections were 12.4, 4.4 and $2.1 \mathrm{~h}$, respectively. Detection probabilities ranged between 0.830 and 0.972 for the 3 click types and 3 sampling schedules (Table 1).

Of the best Risso's dolphin models for the 5 cross-validation datasets, 2 and 4 wk lagged models were 
selected for 2 and 3 datasets, respectively (Table 2). The consistency of predictor variable selection across models can indicate their importance as habitat predic-

Table 1. Grampus griseus and Lagenorhynchus obliquidens. Mean detection probabilities $( \pm \mathrm{SD})$ and correction factors for 3 click types and 3 sub-sampling scenarios based on subsampling of continuous High-frequency Acoustic Recording Package (HARP) data. Correction factors (i.e. the inverse of detection probability) are included as an offset in habitat models. The sub-sampling duration indicates the non-recording duration between 5 min recordings for 5, 10, and 15 min 'off' sampling schedules. PWS = Pacific white-sided

\begin{tabular}{|lccc|}
\hline $\begin{array}{l}\text { Duration } \\
\text { off (min) }\end{array}$ & Risso's & PWS A & PWS B \\
\hline \multicolumn{2}{l}{ Detection probability } & & \\
5 & $0.968(0.002)$ & $0.945(0.003)$ & $0.972(0.005)$ \\
10 & $0.927(0.003)$ & $0.888(0.005)$ & $0.930(0.007)$ \\
15 & $0.882(0.003)$ & $0.830(0.006)$ & $0.883(0.008)$ \\
\multicolumn{2}{l}{ Correction factor } & & \\
5 & 1.033 & 1.058 & 1.028 \\
10 & 1.079 & 1.126 & 1.075 \\
15 & 1.134 & 1.205 & 1.133 \\
\hline
\end{tabular}

tors. The most important predictors were mean SST (100\% of models) and SST CV (80\%). Chl variables $(40 \%)$ and the week $\times$ region interaction $(40 \%)$ were moderately important, while moon duration (20\%) and upwelling $(0 \%)$ were rarely included. The model with the best predictive power on the novel evaluation data included the $4 \mathrm{wk}$ lagged oceanographic data with $3 \mathrm{df}$ spline fits to residual chl and mean SST and $1 \mathrm{df}$ linear fits to the CVs of both chl and SST (Table 2, Fig. 3). Positive relationships exist between the number of hours with clicks present per week and mean SST, log chl residual and chl $\mathrm{CV}$, while a negative relationship is present for SST CV. The spline fit for log chl residual exhibits a slight dip around -2 , while the spline fit for mean SST reaches a maximum around $20^{\circ} \mathrm{C}$ before leveling out. The final model explained $47 \%$ of the deviance (a likelihood-based goodness-of-fit measure). A comparison of the observed and predicted hours with detections illustrates the goodness of fit and predictive power (Fig. 4A). The correlation between observed and predicted hours is positive (Fig. 4D) indicating the model goodness of fit, though a lot of variability remains to be explained.

Table 2. Terms included in best models. The best models are presented for each of the 5 cross-validation datasets of each click type. Null and final Akaike's Information Criterion (AIC) values are presented from the training data and average squared prediction error (ASPE) values are presented from the test data. The dataset with the best predictive model for each click type is represented by bold typeset. Lag times indicate which week model was chosen as the best for each cross-validation model. Environmental variables that were included in the model are indicated and represent the best fit that was chosen followed by the selected degrees of freedom $(\mathrm{L}=$ linear, $\mathrm{p}=$ polynomial, $\mathrm{s}=$ spline). The inclusion of the interaction term of region (north or south) by week is indicated by N. No interaction term was included for Pacific white-sided type (PWS) B as they were only detected at the southern sites. Terms that were not included in the best models are indicated by a dash. The percent of models that included each environmental variable is presented to indicate the importance of that variable across different cross-validation datasets. Variables included in more models are likely to be important indicators of dolphin occurrence. SST = sea surface temperature; $\mathrm{chl}=$ chlorophyll; resid $=$ residual $; \mathrm{CV}=$ coefficient of variation

\begin{tabular}{|c|c|c|c|c|c|c|c|c|c|c|c|}
\hline & $\begin{array}{l}\text { Null } \\
\text { AIC }\end{array}$ & $\begin{array}{l}\text { Final } \\
\text { AIC }\end{array}$ & ASPE & Lag & Upwelling & $\begin{array}{c}\text { Moon } \\
\text { duration }\end{array}$ & $\begin{array}{l}\mathrm{Chl} \\
\text { resid }\end{array}$ & $\begin{array}{l}\mathrm{Chl} \\
\mathrm{CV}\end{array}$ & $\begin{array}{l}\mathrm{SST} \\
\text { mean }\end{array}$ & $\begin{array}{l}\text { SST } \\
\text { CV }\end{array}$ & $\begin{array}{c}\text { Region } \\
\times \text { week }\end{array}$ \\
\hline \multicolumn{12}{|c|}{ Risso's dolphin } \\
\hline Dataset 1 & 3640.2 & 2563.7 & 190.1 & 4 & - & - & - & _- & s3 & $\mathrm{L}$ & - \\
\hline Dataset 2 & 4131.1 & 2470.9 & 169.4 & 4 & - & - & s3 & $\mathbf{L}$ & s3 & $\mathbf{L}$ & - \\
\hline Dataset 3 & 3623.2 & 2464.9 & 393.0 & 4 & - & s2 & - & - & s3 & - & Np3 \\
\hline Dataset 4 & 3848.5 & 2776.5 & 414.5 & 2 & - & - & s3 & $\mathrm{s} 2$ & $\mathrm{~L}$ & s2 & NL \\
\hline Dataset 5 & 4132.8 & 2706.1 & 208.9 & 2 & - & - & $\mathrm{L}$ & - & s2 & s2 & - \\
\hline Models in & hg term ( & & 0 & 20 & 60 & 40 & 100 & 80 & 40 & & \\
\hline \multicolumn{12}{|l|}{ PWS A } \\
\hline Dataset 1 & 2302.3 & 1682.1 & 187.0 & 2 & s3 & - & - & - & - & s3 & $\mathrm{Np} 2$ \\
\hline Dataset 2 & 2265.6 & 1743.9 & 130.4 & 4 & - & - & $\mathrm{L}$ & $\mathrm{L}$ & $\mathrm{L}$ & s3 & Np3 \\
\hline Dataset 3 & 2571.0 & 2004.6 & 51.6 & 16 & s3 & - & - & - & - & - & Np2 \\
\hline Dataset 4 & 2510.7 & 2109.0 & 18.8 & 4 & - & - & - & - & $\mathbf{L}$ & s3 & Np2 \\
\hline Dataset 5 & 2230.4 & 1285.1 & 174.3 & 16 & - & s3 & $\mathrm{L}$ & - & $\mathrm{L}$ & - & Np2 \\
\hline Models in & ng term & & 40 & 20 & 40 & 20 & 60 & 60 & 100 & & \\
\hline \multicolumn{12}{|l|}{ PWS B } \\
\hline Dataset 1 & 942.9 & 367.1 & 500.3 & 8 & s3 & - & - & - & - & s3 & $\mathrm{p} 2$ \\
\hline Dataset 2 & 2479.0 & 563.1 & 5.4 & $\mathbf{0}$ & s3 & - & - & - & s3 & s3 & p2 \\
\hline Dataset 3 & 2427.9 & 695.8 & 5.6 & 1 & s3 & s2 & - & - & s3 & s3 & p2 \\
\hline Dataset 4 & 2493.9 & 529.5 & 111.0 & 16 & - & $\mathrm{L}$ & $\mathrm{L}$ & - & L & s3 & $\mathrm{L}$ \\
\hline Dataset 5 & 2294.6 & 507.2 & 30.6 & 16 & - & $\mathrm{L}$ & s3 & - & L & s3 & p2 \\
\hline \multicolumn{3}{|c|}{ Models including term (\%) } & 60 & 60 & 40 & 0 & 80 & 100 & 100 & & \\
\hline
\end{tabular}



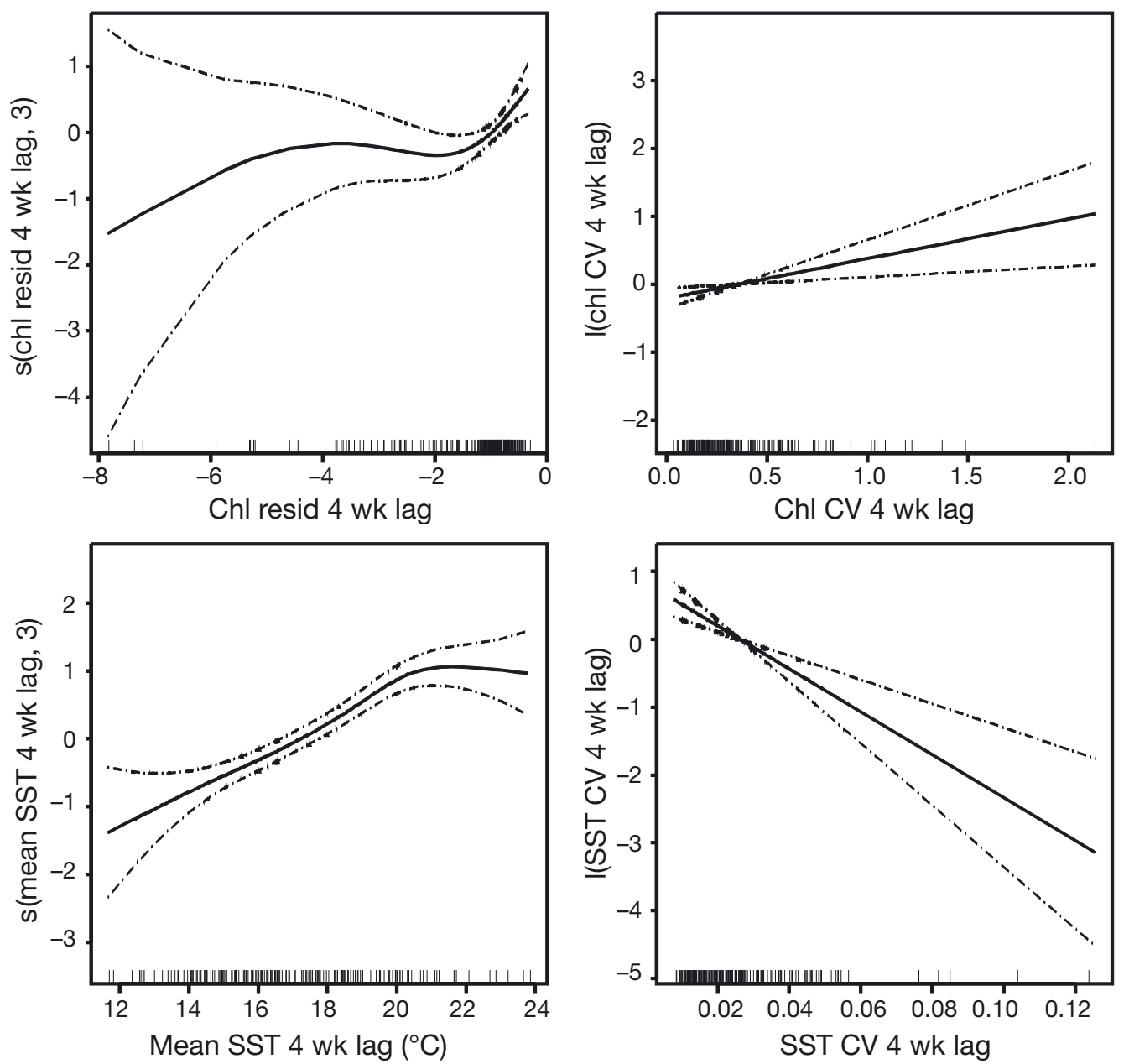

Fig. 3. Grampus griseus. Modeled partial fits of oceanographic variables to Risso's dolphin hours detected per week. The solid line represents the best fit while dotted lines represent the confidence intervals. All plots are at the same vertical scale so that the strength of the slope indicates the importance of the variable in the model. The $y$-axis label indicates the fit type $(l=l i n e a r$, $\mathrm{s}=$ spline) and the degrees of freedom. Rugplot at the bottom indicates location of sample values. SST $=$ sea surface temperature; $\mathrm{chl}=$ chlorophyll $;$ resid $=$ residual $; \mathrm{CV}=$ coefficient of variation

Of the 5 best PWS A click models, the 2, 4 and $16 \mathrm{wk}$ lagged models were selected for 1, 2, and 2 datasets, respectively (Table 2 ). The week $\times$ region interaction $(100 \%)$ and both SST variables $(60 \%)$ were selected more often than chl residual (40\%), upwelling (40\%), moon duration (20\%) and chl CV (20\%). The model with the best predictive power on the novel evaluation data incorporated the $4 \mathrm{wk}$ lagged data with a $1 \mathrm{df}$ linear term for mean SST, a 3 df spline fit for SST CV and a $2 \mathrm{df}$ polynomial fit to the week $\times$ region interaction (Table 2, Fig. 5). The relationships between number of hours with PWS A clicks and SST variables were generally negative, and the SST CV relationship exhibited wide confidence intervals due to low sample size at higher values. Hours per week with detections peaked during the summer in northern regions and during the fall through winter in the southern regions.
The final model had a relatively poor fit to the data the model was built upon, explaining $24 \%$ of the model deviance (Fig. 4B). A slight positive correlation between observed and predicted hours was evident and suggests that most of the variability remains to be explained (Fig. 4E).

PWS B models had the least consistency in temporal lag selection: 0 (current conditions), 1, 8, and 16 wk lag models were selected for 1, 1, 1 and 2 datasets respectively (Table 2). There was greater consistency in variable selection across models. The most important variables were SST CV $(100 \%)$ and week $\times$ region interaction $(100 \%)$, and mean SST (80\%) while upwelling $(60 \%)$, moon duration $(60 \%)$, chl residual $(40 \%)$, and chl CV (0\%) were selected less often. The model with the best predictive power on novel data incorporated the $0 \mathrm{wk}$ lagged oceanographic data with 

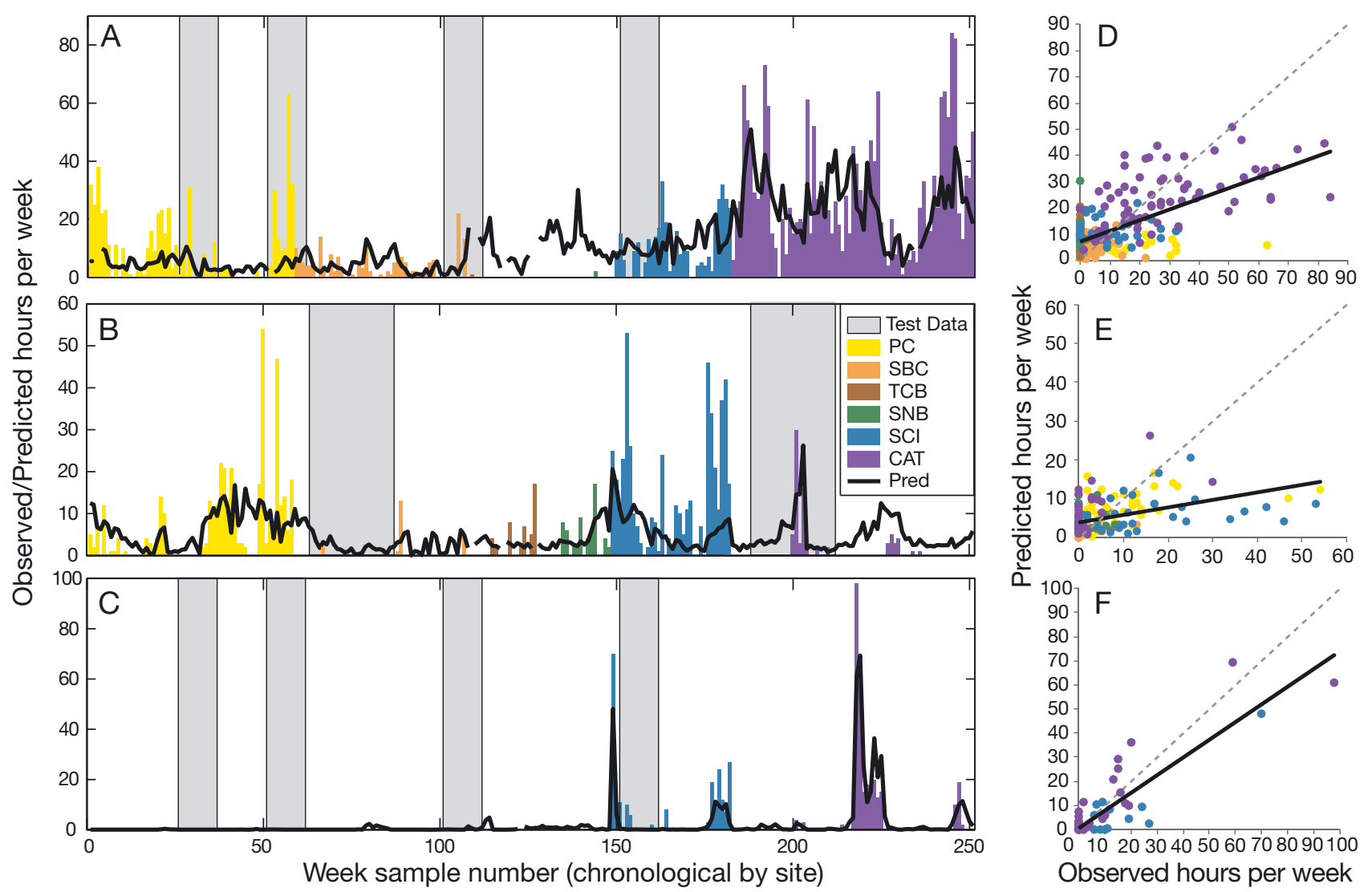

Fig. 4. Grampus griseus and Lagenorhynchus obliquidens. Observed and predicted values from the best models for (A,D) Risso's dolphin, (B,E) Pacific white-sided dolphin type (PWS) A, and (C,F) PWS B. Observed values are plotted by sample number chronologically by site in A, B and C, and sample observations and predictions are compared in D, E, and F. Observed values are represented by colored bars where the color indicates the site. See Fig. 1 for site abbreviations. The black line represents predicted values from the model. Breaks in the prediction line indicate the absence of environmental data which were not included in models. In the chronological plots, data that were removed during model building but used to test predictive power are highlighted by light gray boxes. In the scatter plots, the best fit line is indicated by the black line and a one-to-one correspondence (perfect prediction) is indicated by the thin gray dashed line.

3 df spline fits for upwelling, mean SST, and SST CV and a $2 \mathrm{df}$ polynomial fit to the week $\times$ region interaction (Table 2, Fig. 6). Number of hours with PWS B clicks peaked at a mean SST of $18^{\circ} \mathrm{C}$ and fell off rapidly at lower temperatures. A positive relationship between click hours and upwelling is suggested, with a leveling off at high values $\left(>150 \mathrm{~m}^{3} \mathrm{~s}^{-1}\right)$. The relationship between hours with PWS B detections and SST CV was generally negative and exhibited wide confidence intervals due to low sample size at higher values, suggesting it should be interpreted with caution. PWS B clicks were only heard at southern sites where there are low detections during summer and a seasonal peak in late fall to early winter. The final model explained $82 \%$ of the deviance (Fig. 4C). The positive correlation between observed and predicted hours approaches 1:1 (Fig. 4F), illustrating the high predictive power of this model.

\section{DISCUSSION}

The present study is one of the first to use passive acoustic monitoring data to model delphinid habitat (e.g. Hastie et al. 2005, Skov \& Thomsen 2008). Strong relationships are found between delphinid acoustic activity and dynamic environmental features on a longterm and fine-scale temporal resolution that is not feasible with visual monitoring. In particular, mean SST and low SST spatial variability (SST CV) were important predictors of acoustic activity for all 3 delphinid groups, seasonal variability proved to be an important predictor for both Pacific white-sided dolphin groups, and chlorophyll abundance and variability were important for Risso's dolphins. Defining the response variable as a function of echolocation clicks, which are produced most often during foraging (Norris et al. 1994), increases the likelihood that models incorporating these 
environmental features represent foraging habitat. By understanding the relationship to dynamic features, models can provide better predictive power and allow investigation into the mechanisms causing changes in delphinid distribution and abundance.

The incorporation of time-lagged environmental data in acoustic-based habitat models can provide insight into the oceanographic aggregating mechanisms of different dolphin prey types. Dolphin response to current conditions at a fixed location would indicate an advanced ecosystem containing aggregations of higher trophic levels that attract dolphin prey, as found in downwelling convergence zones or eddies that are moving past the location. Conversely, a time lag between environmental conditions and dolphin occurrence would indicate time for successional processes, as higher trophic levels develop and support delphinid prey, as found in coastal upwelling and eddy formation. The best model of PWS B clicks included environmental data at the current time, suggesting foraging on prey that aggregate at fronts or convergence zones, while the best models of Risso's dolphin and PWS A clicks included environmental data at a $4 \mathrm{wk}$ time lag, suggesting foraging on prey that respond to successional processes following events such as upwelling. The combination of a $4 \mathrm{wk}$ lag in low spatial variability in temperature (SST CV) and high chl seems counterintuitive, but may represent the need for calm relaxation periods following upwelling for water stratification and phytoplankton bloom development (Huntsman \& Barber 1977, Jones \& Halpern 1981) that lead to abundant food for the higher trophic level prey (Lasker
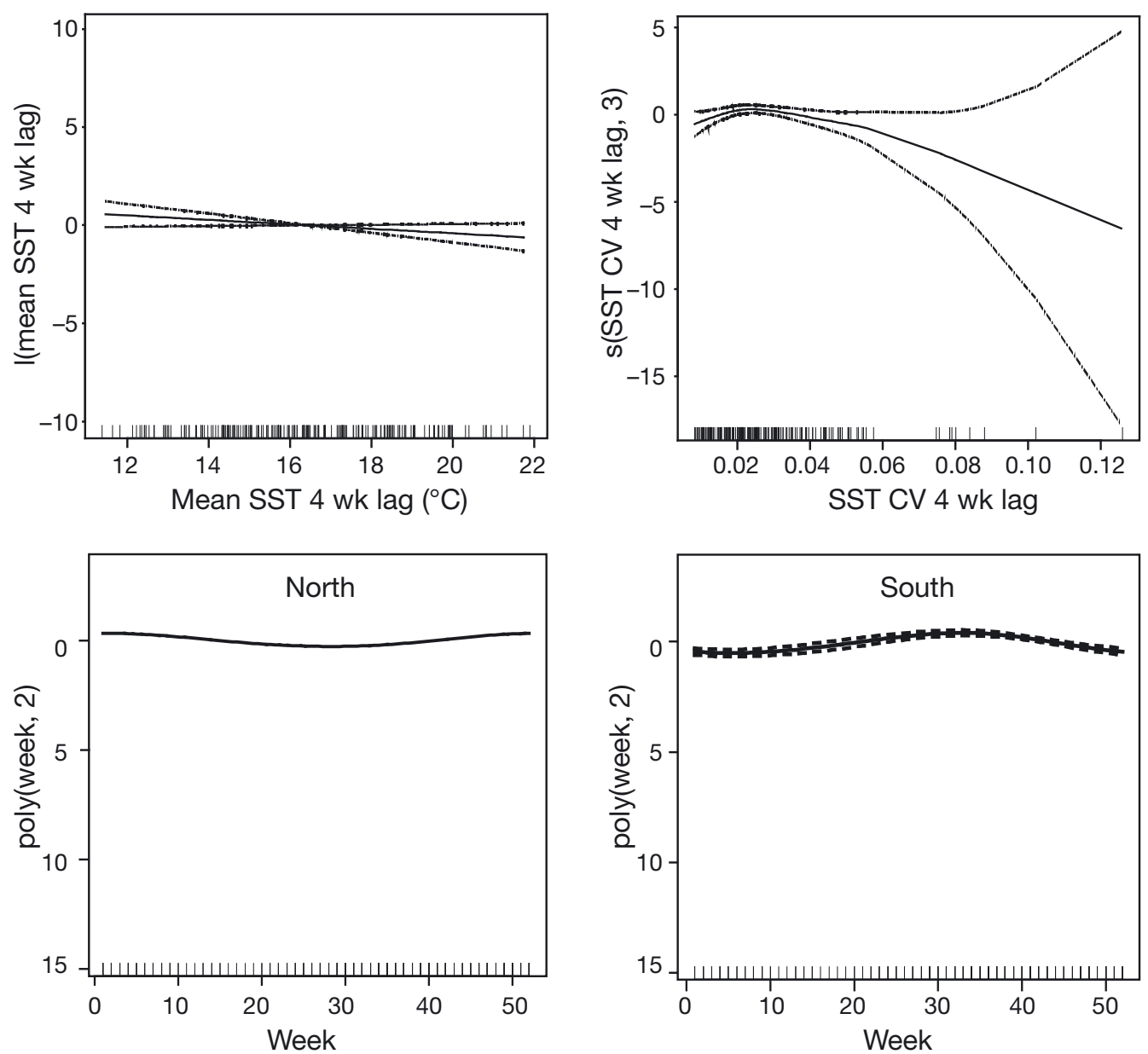

Fig. 5. Lagenorhynchus obliquidens. Modeled partial fits of oceanographic variables to Pacific white-sided dolphin click type A hours detected per week. The solid line represents the best fit while dotted lines represent the confidence intervals. Plots are at the same vertical scale so that the strength of the slope indicates the importance of the variable in the model. The $y$-axis label indicates the fit type $(\mathrm{l}=$ linear, poly = polynomial, $\mathrm{s}=$ spline $)$ and the degrees of freedom. Rugplot at the bottom indicates location of sample values. The lower 2 plots represent the interaction between region and week such that the left and right plots are for the northern and southern regions, respectively. The interaction plots were created with R using mgcv because S-Plus was not able to plot interactions terms. The 2 algorithms produced similar model fits for sea surface temperature (SST) and SST coefficient of variation (CV), which suggests that these interaction plots are valid for the S-Plus algorithm 
1975, 1978) of Risso's and Pacific white-sided dolphins. This hypothesis requires that these productive waters remain in a fixed location over time (e.g. Vinogradov 1981), and it is unknown if this is a reasonable assumption in this region. An alternative hypothesis for the $4 \mathrm{wk}$ time lag is that prey aggregations may be moving with periodic features found in the SCB. For example, high amplitude current fluctuations, which may be attributable to eddy advection or coastally trapped waves, exhibit 20 to $30 \mathrm{~d}$ periodicity at SCB basins (Hendricks 1977, Hickey 1992).

The modeled relationships between dolphin acoustic activity and environmental variables are reasonable when compared with what is known about the ecology of each group. The models suggest Risso's dolphins prefer warmer waters, peaking at $20^{\circ} \mathrm{C}$ and above, while PWS B peak in moderate waters around $18^{\circ} \mathrm{C}$ and PWS A prefer cooler waters. Similarly, Risso's dol- phins have been observed inhabiting warm-temperate waters (Kruse 1989, Tynan 1997, Benson et al. 2002) and expanding their range north during extended warm periods (Leatherwood et al. 1980), while studies of northern Pacific white-sided dolphins indicate preference for cooler waters (Benson et al. 2002, Becker 2007). The temperature difference between the 2 Pacific white-sided dolphin types reflects the southerly and northerly distribution of their echolocation activity and possibly population ranges (Soldevilla et al. 2010b). Additionally, the seasonal variability described by Soldevilla et al. (2010b) was incorporated into the models. A positive relationship to the upwelling index was an important predictor for PWS B click detections, which seems counter-intuitive given the negative relationship to SST CV. This discrepancy may be a result of the use of local data for SST CV compared to regional values general to the entire SCB for the upwelling index,
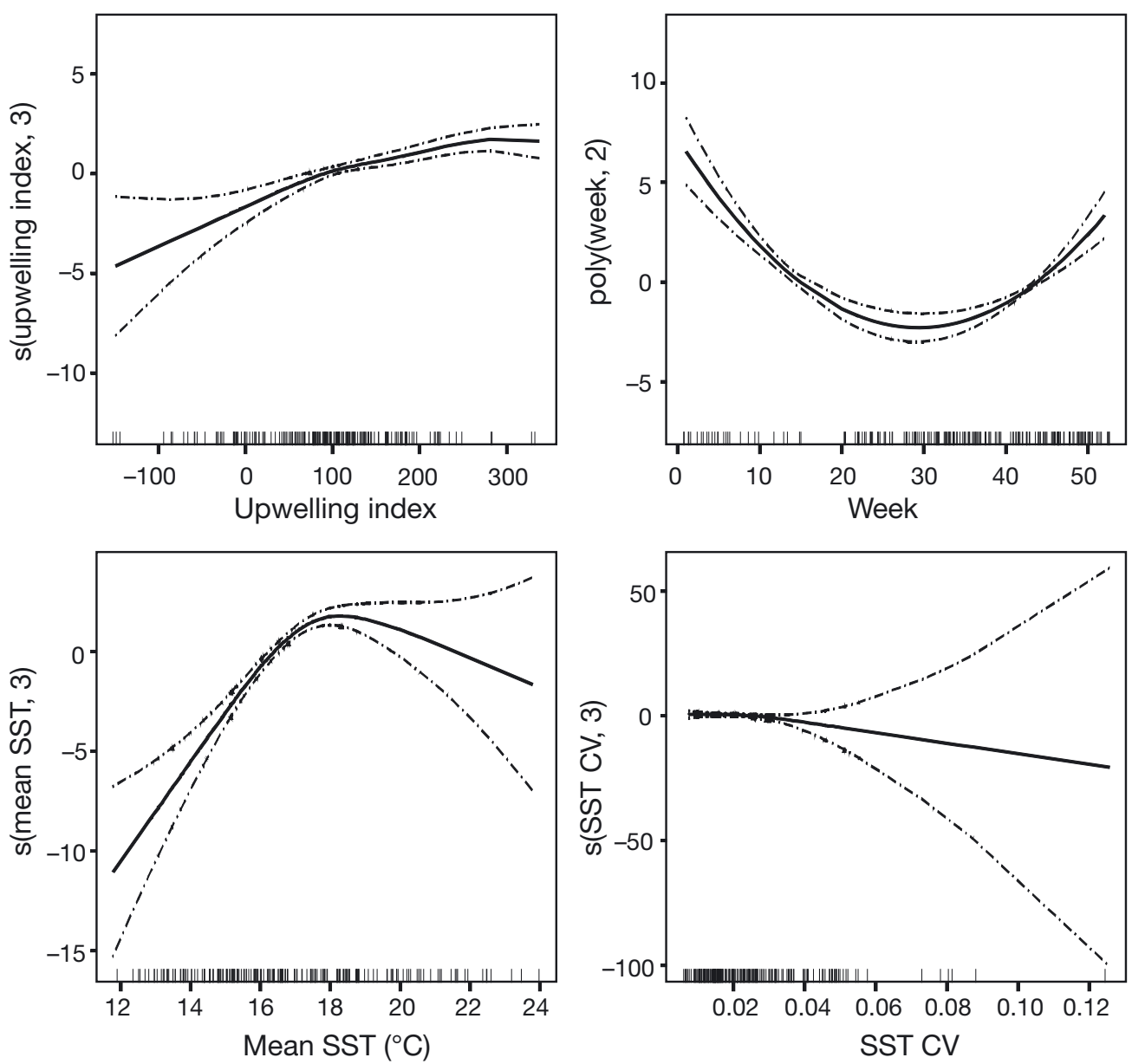

Fig. 6. Lagenorhynchus obliquidens. Modeled partial fits of oceanographic variables to Pacific white-sided dolphin click type B hours detected per week. The solid line represents the best fit while dotted lines represent the confidence intervals. Plots are at the same vertical scale so that the strength of the slope indicates the importance of the variable in the model, with the exception of SST CV which had large confidence intervals. The $y$-axis label indicates the fit type (poly = polynomial, $\mathrm{s}=\mathrm{spline)}$ and the degrees of freedom. Rugplot at the bottom indicates location of sample values. SST $=$ sea surface temperature; CV $=$ coefficient of variation 
or it may be a result of the high uncertainty in the relationship to SST CV at higher values. The regional upwelling index may reflect basin-wide oceanographic changes that support movements up from Baja California, Mexico. Local upwelling indices, which can provide important information about prey aggregating mechanisms, may be important for all dolphins and should be considered in future models.

The explained deviance for the best models of the 3 dolphin groups spanned a wide range, with values of 24, 47, and $82 \%$ for PWS A, Risso's, and PWS B, respectively. These explained deviances are generally an improvement over those found in visual survey habitat studies of a variety of species, which range between 1 and 43\% (Ferguson 2005, Becker 2007). The moderate to high explained deviances found in this study may indicate that the models include some of the most important variables needed to explain dolphin echolocation activity, while lower fits indicate that other data, such as measures of prey abundance, or different time lags may be important. Additionally, the better fit of these spatio-temporal models compared to spatial visual survey models may indicate that temporal variation, such as seasonality, is inherently more predictable than spatial variability. It is interesting to note that quality of fit appears to be site-specific for Risso's and PWS A models (Fig. 4). An examination of additional explanatory variables including bathymetric differences or additional oceanographic differences between the sites that affect prey distribution or the occurrence of predators or competitors as well as increased site coverage in the region may improve explanatory power of models in this region.

While explained deviances of these models are moderate to high, the variability among the 3 groups may reflect differences in the portion of the dolphins' range that is covered by this study, in the life history of the animals, or in the quantity or quality of data compared to the complexity of habitat to be modeled. The study area includes the northern extent of the PWS B group range, and the high fit may reflect the incorporation of both prime habitat and non-habitat into the model, while PWS A is heard throughout and beyond the study area so that the entire area represents viable habitat only which may be more difficult to precisely model. Similarly, dolphins may not occur in the study area when environmental conditions are good because they are inhabiting areas outside the study area where conditions are better, resulting in lower observed occurrences than predicted. For these reasons, future studies should extend the spatial range of the study area to include more of, and extend beyond, the dolphins' known ranges. Differences in model explanatory power may reflect differences in prey preferences, as suggested by Soldevilla et al. (2010b) for
Pacific white-sided dolphin types based on differences in diel activity and spatial occurrence. Pacific whitesided dolphins are opportunistic foragers on variable prey types. It is possible that PWS B represents a population adapted toward a specialist approach to foraging while PWS A represents a generalist approach and therefore multiple habitat preferences to model. Complex habitat models require larger sample sizes (Becker 2007), so more data may be needed to improve PWS A models. Finally, it is possible that the especially high explained deviance for PWS B is a byproduct of the generally low number of observed detections for this dolphin group such that the model could always predict low values. In the case of the best PWS B model, the training data included high and low observed detections, while the test set had only low observed detections. However, the remaining models which included test sets with more variability in observed detections include similar variables supporting the validity of the best model.

An important caveat to predictive modeling is that the statistical significance of terms included in models does not necessarily imply the ecological significance of those variables to the dolphins (Hamazaki 2002). The predictive models presented in this study provide insight into ecological relationships that can be used to develop and test appropriate hypotheses about the mechanisms behind dolphin occurrence. Gaps in our mechanistic understanding include knowledge of both dolphin prey type and prey response to the environment. Risso's dolphins are known to feed primarily on cephalopods (Clarke 1996), and many species of squid are found off California (Okutani \& McGowan 1969, Roper \& Young 1975), though stomach content analyses are available for only 1 Risso's dolphin stranded off California almost 50 yr ago (Orr 1966). On the other hand, Pacific white-sided dolphins are opportunistic foragers and feed on the most abundant, appropriately sized prey (Brown \& Norris 1956, Fitch \& Brownell 1968, Stroud et al. 1981, Walker et al. 1986), so their prey types likely change over time. Concurrent sampling of dolphins and their prey and comparison of habitat models of potential prey species (e.g. Schismenou et al. 2008) with dolphin habitat models could help determine which prey species are most important in dolphins' diets during the study period.

Remotely sensed SST and chl data can indicate the presence of fronts and areas of high productivity; however, the ecological structure of the regions, including the specific composition of phytoplankton, zooplankton and fish assemblages, can only be determined through in situ oceanographic sampling, including water samples, net tows and multi-frequency acoustic backscatter. In situ sampling of some properties could be incorporated into moorings at the HARP location, 
including temperature, salinity, current meters, fluorescence and multi-frequency active acoustics. However, automated technologies to determine prey species identity from active acoustics are still under development, so concurrent ship-based marine mammal surveys and oceanographic sampling may be a better venue for exploring mechanisms affecting prey and dolphin abundance. Concurrent dolphin acoustic and environmental sampling of this sort would allow finer resolution of prey field and water properties resulting in a better indication of water mass and frontal structure, and allowing mechanistic questions to be asked when using autonomous acoustic data. Models based on remotely sensed data remain important for resource managers who do not have access to in situ oceanographic data in real-time.

This study indicates the importance of temporal variability in predicting dolphin occurrence. While this study was limited to incorporating a consistent lag time for all oceanographic variables in each model, it seems likely that multiple lag times are important, both because succession processes might result in abiotic and biotic variables having different lags, and also because these dolphin species feed on a variety of prey, each of which may be responding to features at different time lags. While this could be examined using GAM models, inclusion of so many hypothesis tests can result in Type 1 errors. Numerous methods for analyzing time series are available and these could be used to identify a greater variety of temporal correlations and phase shifts (i.e. lag times) than the regression models in this study could. Temporal crosscorrelation techniques can incorporate multiple variables and relate both frequency of occurrence and phase shifts more easily than the time-lagged GAM models described here. Unfortunately these techniques were not feasible due to the gaps present in our time series. Future studies should minimize large time-series gaps; data with small gaps may be analyzed using techniques such as ARIMA or Kalman filtering.

Modeling the occurrence of echolocating dolphins depends on the ability to detect their click production. Factors which may affect the likelihood of detecting calling animals include sound propagation conditions and acoustic masking. Sound propagation conditions may vary across sites and seasons leading to spatial and temporal variability in detection probability; however, conditions are typically downward refracting in the SCB across seasons and sites. Examination of click detection of all species does not indicate a strong bias for any site or season. Additionally, at the frequencies used for echolocation, attenuation severely limits detection range, and therefore the potential for significant variation owing to seasonal variations in propaga- tion conditions is reduced. Vessels, sonars, other animals, rain, wind and waves may produce sounds that mask the echolocation clicks of our chosen species so it is important to consider spatial and temporal variability in these sources. Preliminary analyses indicate that vessel noise is consistent throughout the year at all sites except Santa Catalina Island where there is an increase in occurrence during the summer (May to September), while wind and rain noise within the frequency band of clicks occurs minimally throughout the year. Future studies should explicitly incorporate metrics of ambient noise into habitat models.

The models presented here are based on presence/ absence modeling from fixed passive acoustic sensors at multiple sites, providing unique insight into the amount of time animals spend in a given habitat. This is an important indicator of habitat quality and spatiotemporal usage patterns that is necessary for managers and planners to determine when and where cetaceans are likely to be found and how anthropogenic events may impact them. However, to determine the long-term impacts of events on a population, predicting the numbers of individuals is also critical, yet cetacean abundance estimation from passive acoustic monitoring remains a work in progress (e.g. Barlow \& Taylor 2005, Marques et al. 2009, Whitehead 2009) and behavioral variability in sound production remains a challenge. At this point, incorporating the strengths of both visual and acoustic survey methods offers the best chance for realizing all features of habitat importance.

\section{CONCLUSION}

Temporal predictive models of cetacean habitat provide researchers and managers with the ability to examine how dynamic ocean processes affect the occurrence of cetaceans in a specific area of interest. The combination of remotely sensed oceanographic data and long-term acoustic sampling of acoustically classifiable cetaceans such as Risso's and Pacific white-sided dolphins offer the potential to examine these temporally changing patterns and understand the time scales of importance. The models presented here for Risso's and Pacific white-sided dolphins indicate that processes occurring as much as 16 wk prior may explain or predict dolphin occurrence, although the models with best predictive power were based on $0 \mathrm{wk}$ and $4 \mathrm{wk}$ lagged oceanographic data. The ability to predict dolphin occurrence with timelagged data is especially pertinent for managers who wish to minimize the impact of anthropogenic events by enabling them to plan events several weeks in advance. 
Acknowledgements. The authors thank all the personnel who were involved in instrument development, deployment, recovery and data acquisition including: S. Baumann, H. Basset, C. Berchock, G. S. Campbell, G. Crocker, C. Garsha, M. Gassmann, E. E. Henderson, M. F. McKenna, L. M. Munger, E. H. Roth, N. Rubio, L. E. Williams, and B. Hurley. M. Kahru provided remote satellite data and software support. J. P. Barlow, S. Baumann, D. M. Checkley, B. Cornuelle, E. E. Henderson, L. M. Munger, B. Rao, J. V. Redfern, M. A. Roch and 4 anonymous reviewers provided insightful discussions and/or constructive critique of earlier versions of this manuscript. We thank the ARCS Foundation, Los Angeles chapter for supporting M.S.S. and F. Stone, E. Young, and C. Collins for supporting our work through the Navy CNO-N45 and the Naval Postgraduate School.

\section{LITERATURE CITED}

Barlow J, Forney KA (2007) Abundance and population density of cetaceans in the California Current ecosystem. Fish Bull 105:509-526

Barlow J, Taylor BL (2005) Estimates of sperm whale abundance in the northeastern temperate Pacific from a combined acoustic and visual survey. Mar Mamm Sci 21: $429-445$

Barrett-Lennard LG, Ford JKB, Heise KA (1996) The mixed blessing of echolocation: differences in sonar use by fisheating and mammal-eating killer whales. Anim Behav 51: 553-565

Baumgartner MF (1997) The distribution of Risso's dolphin (Grampus griseus) with respect to the physiography of the northern Gulf of Mexico. Mar Mamm Sci 13:614-638

Baumgartner MF, Mullin KD, May LN, Leming TD (2001) Cetacean habitats in the northern Gulf of Mexico. Fish Bull 99:219-239

Becker EA (2007) Predicting seasonal patterns of California cetacean density based on remotely sensed environmental data. PhD thesis, University of California, Santa Barbara, CA

Benson SR, Croll DA, Marinovic BB, Chavez FP, Harvey JT (2002) Changes in the cetacean assemblage of a coastal upwelling ecosystem during El Niño 1997-98 and La Niña 1999. Prog Oceanogr 54:279-291

Brink KH, Muench RD (1986) Circulation in the Point Conception-Santa Barbara channel region. J Geophys Res 91: 877-895

Brown DH, Norris KS (1956) Observations of captive and wild cetaceans. J Mammal 37:311-326

Caldeira RMA, Marchesiello P, Nezlin NP, DiGiacomo PM, McWilliams JC (2005) Island wakes in the Southern California Bight. J Geophys Res 110: C11012 doi: 10-1029/ 2004JC002671

> Clarke MR (1996) Cephalopods as prey. III. Cetaceans. Philos Trans R Soc Lond B Biol Sci 351:1053-1065

Clarke MR, Pascoe PL (1985) The stomach contents of a Risso's dolphin (Grampus griseus) stranded at Thurlestone, South Devon. J Mar Biol Assoc UK 65:663-665

Croll DA, Marinovic B, Benson S, Chavez FP, Black N, Ternullo R, Tershy BR (2005) From wind to whales: trophic links in a coastal upwelling system. Mar Ecol Prog Ser 289:117-130

> DiGiacomo PM, Holt B (2001) Satellite observations of small coastal ocean eddies in the Southern California Bight. J Geophys Res 106:22521-22543

Dohl TP, Guess RC, Duman ML, Helm RC (1983) Cetaceans of central and northern California, 1980-1983: status, abun- dance, and distribution. Pacific OCS Region Minerals Management Service, US Department of the Interior Contract \#14-12-0001-29090, Santa Cruz, CA

Emery KO (1960) The sea off Southern California. John Wiley \& Sons, New York, NY

Ferguson MC (2005) Cetacean population density in the Eastern Pacific Ocean: analyzing patterns with predictive spatial models. PhD dissertation, University of California, San Diego, CA

Ferguson MC, Barlow J, Fiedler P, Reilly SB, Gerrodette T (2006) Spatial models of delphinid (family Delphinidae) encounter rate and group size in the eastern tropical Pacific Ocean. Ecol Modell 193:645-662

> Fiedler PC, Reilly SB, Hewitt RP, Demer D and others (1998) Blue whale habitat and prey in the California Channel Islands. Deep-Sea Res II 45:1781-1801

Fitch JE, Brownell RL (1968) Fish otoliths in cetacean stomachs and their importance in interpreting feeding habits. J Fish Res Board Can 25:2561-2574

Forney KA (2000) Environmental models of cetacean abundance: reducing uncertainty in population trends. Conserv Biol 14:1271-1286

Forney KA, Barlow J (1998) Seasonal patterns in the abundance and distribution of California cetaceans, 19911992. Mar Mamm Sci 14:460-489

Green G, Brueggeman JJ, Grotefendt RA, Bowlby CE, Bonnell ML K. C. Balcomb KC III (1992) Cetacean distribution and abundance off Oregon and Washington. In: Brueggeman J (ed) Oregon and Washington marine mammal and seabird surveys. Final report for Pacific OCS Region, Minerals Management Service, US Department of the Interior, Los Angeles, California, p 1-100

Gregr EJ, Trites AW (2001) Predictions of critical habitat for five whale species in the waters of coastal British Columbia. Can J Fish Aquat Sci 58:1265-1285

Hamazaki T (2002) Spatiotemporal prediction models of cetacean habitats in the mid-western North Atlantic Ocean (from Cape Hatteras, North Carolina, USA to Nova Scotia, Canada). Mar Mamm Sci 18:920-939

Hastie TJ, Tibshirani RJ (1990) Generalized additive models. Chapman and Hall, New York, NY

Hastie GD, Swift RJ, Slesser G, Thompson PM, Turrell WR (2005) Environmental models for predicting oceanic dolphin habitat in the Northeast Atlantic. ICES J Mar Sci 62:760-770

Hendricks T (1977) Measurements of subthermocline currents. Southern California Coastal Water Research Project Annual Report for the Year Ended 30 June 1976:63-70

Hickey BM (1979) The California current system-hypotheses and facts. Prog Oceanogr 8:191-279

Hickey BM (1992) Circulation over the Santa Monica-San Pedro basin and shelf. Prog Oceanogr 30:37-115

Huntsman SA, Barber RT (1977) Primary production off northwest Africa: the relationship to wind and nutrient conditions. Deep-Sea Res II 24:25-33

Jaquet N (1996) How spatial and temporal scales influence understanding of sperm whale distribution: a review. Mar Mamm Sci 26:51-65

Jaquet N, Whitehead H (1996) Scale-dependent correlation of sperm whale distribution with environmental features and productivity in the South Pacific. Mar Ecol Prog Ser 135: 1-9

Jones BH, Halpern D (1981) Biological and physical aspects of a coastal upwelling event observed during March-April 1974 off northwest Africa. Deep-Sea Res II 28:71-81

Kolpack RL (1971) Biological and oceanographical survey of the Santa Barbara Channel oil spill 1969-1970, Vol II: University of Southern California, Los Angeles, CA 
Kruse SL (1989) Aspects of the biology, ecology, and behavior of Risso's dolphins (Grampus griseus) off the California coast. MSc thesis, University of California, Santa Cruz, CA

Kruse S, Caldwell DK, Caldwell MC (1999) Risso's dolphin Grampus griseus (G. Cuvier, 1812). In: Ridgway SH, Harrison R (eds) Handbook of marine mammals, Vol 6. Academic Press, Cambridge, p 183-212

Lasker R (1975) Field criteria for survival of anchovy larvae: the relation between inshore chlorophyll maximum layers and successful first feeding. Fish Bull 73:453-462

Lasker R (1978) The relations between oceanographic conditions and larval anchovy food in the California Current: identification of factors contributing to recruitment failure. Rapp P-V Reun Cons Int Explor Mer 173:212-230

Leatherwood S, Perrin WF, Kirby VL, Hubbs CL, Dahlheim M (1980) Distribution and movements of Risso's dolphin, Grampus griseus, in the eastern North Pacific. Fish Bull 77:951-963

Leatherwood S, Reeves RR, Bowles AE, Stewart BS, Goodrich KR (1984) Distribution, seasonal movements, and abundance of Pacific white-sided dolphins in the eastern North Pacific. Sci Rep Whales Res Inst Tokyo 35:129-157

Lux CA, Costa AS, Dizon AE (1997) Mitochondrial DNA population structure of the Pacific white-sided dolphin. Rep Int Whaling Comm 47:645-652

Marques TA, Thomas L, Ward J, DiMarzio N, Tyack PL (2009) Estimating cetacean population density using fixed passive acoustic sensors: an example with Blainville's beaked whales. J Acoust Soc Am 125:1982-1994

McCullagh P, Nelder JA (1999) Generalized linear models. Chapman and Hall/CRC, New York, NY

Norris KS, Wursig B, Wells RS, Wursig M (1994) The Hawaiian spinner dolphin. University of California Press, Berkeley, CA

Nowacek DP (2005) Acoustic ecology of foraging bottlenose dolphins (Tursiops truncatus), habitat-specific use of three sound types. Mar Mamm Sci 21:587-602

Okutani T, McGowan JA (1969) Systematics, distribution, and abundance of the epiplanktonic squid (Cephalopoda, Decapoda) larvae of the California Current April, 1954March, 1957. Scripps Institution of Oceanography, La Jolla, CA

Orr RT (1966) Risso's dolphin on the Pacific coast of North America. J Mammal 47:341-343

Redfern JV, Ferguson MC, Becker EA, Hyrenbach KD and others (2006) Techniques for cetacean-habitat modeling. Mar Ecol Prog Ser 310:271-295

Reid JL, Roden GI, Wyllie JG (1958) Studies of the California Current System. Cal Coop Ocean Fish Invest Prog Rep 1 July 1956-1 January 1958:27-56

Roper CFE, Young RE (1975) Vertical distribution of pelagic cephalopods. Smithson Contrib Zool 209:1-51

Schismenou E, Giannoulaki M, Valavanis V, Somarakis S (2008) Modeling and predicting potential spawning habitat of anchovy (Engraulis encrasicolus) and round sardinella (Sardinella aurita) based on satellite environmental information. Hydrobiologia 612:201-214

Editorial responsibility: Hans Heinrich Janssen, Oldendorf/Luhe, Germany
Shane SH (1994) Occurrence and habitat use of marine mammals at Santa Catalina Island, California from 1983-91. Bull South Calif Acad Sci 93:13-29

Shepard FP, Emery KO (1941) Submarine topography off the California coast: canyons and tectonic interpretation. Spec Pap Geol Soc Am 31:1-171

Skov H, Thomsen F (2008) Resolving fine-scale spatio-temporal dynamics in the harbour porpoise Phocoena phocoena. Mar Ecol Prog Ser 373:173-186

Soldevilla MS, Henderson EE, Campbell GS, Wiggins SM, Hildebrand JA, Roch MA (2008) Classification of Risso's and Pacific white-sided dolphins using spectral properties of echolocation clicks. J Acoust Soc Am 124:609-624

> Soldevilla MS, Wiggins SM, Hildebrand JA (2010a) Spatial and temporal patterns of Risso's dolphin echolocation in the Southern California Bight. J Acoust Soc Am 127: $124-132$

Soldevilla MS, Wiggins SM, Hildebrand JA (2010b) Spatiotemporal comparison of Pacific white-sided dolphin echolocation click types. Aquat Biol 9:49-62

Stroud RN, Fiscus CH, Kajimura H (1981) Food of the Pacific white-sided dolphin, Lagenorhynchus obliquidens, Dall's porpoise, Phocoenoides dalli, and northern fur seal, Callorhinus ursinus, off California and Washington. Fish Bull 78: 951-959

Tynan CT (1997) Cetacean distributions and oceanographic features near the Kerguelen Plateau. Geophys Res Lett 24:2793-2796

Van Parijs SM, Corkeron PJ (2001) Vocalizations and behaviour of Pacific humpback dolphins Sousa chinensis. Ethology 107:701-716

Vinogradov ME (1981) Ecosystems of equatorial upwellings. In: Longhurst AR (ed) Analysis of marine ecosystems. Academic Press, San Francisco, CA, p 69-94

Walker WA, Leatherwood S, Goodrick KR, Perrin WF, Stroud RK (1986) Geographic variation and biology of the Pacific white-sided dolphin, Lagenorhynchus obliquidens, in the north-eastern Pacific. In: Bryden MM, Harrison R (eds) Research on dolphins. Clarendon Press, Oxford, p 441-465

Ward J, DiMarzio N, Jarvis S, Moretti D, Morrisey R, Johnson M, Tyack P (2009) Mesoplodon densirostris transmission beam pattern estimated from passive acoustic bottom mounted hydrophones and DTag recordings on multiple whales. Proc 4th Int Workshop on Detection, Classification and Localization of Marine Mammals Using Passive Acoustics, Pavia, Italy

Whitehead H (2009) Estimating abundance from onedimensional passive acoustic surveys. J Wildl Manag 73: 1000-1009

Wooster WS, Jones JH (1970) California undercurrent off northern Baja California. J Mar Res 28:235-250

Yen PPW, Sydeman WJ, Hyrenbach KD (2004) Marine bird and cetacean associations with bathymetric habitats and shallow-water topographies: implications for trophic transfer and conservation. J Mar Syst 50:79-99

Submitted: January 28, 2010; Accepted: November 10, 2010 Proofs received from author(s): February 1, 2011 